\title{
Evaluation of Biochemical Changes in Diabetic Rats Treated with Aegle marmelos (L.) Methanolic Leaf Extract
}

\author{
Ravi Babu Birudu, Padmavathi Pamulapati, Sathish Kumar Manoharan' \\ Department of Zoology and Aquaculture, Acharya Nagarjuna University, Guntur, 'Department of Pharmacology, Bapatla College of Pharmacy, Bapatla, Andhra \\ Pradesh, India
}

\begin{abstract}
Background: Aegle marmelos (L.) Correa is a widely found plant in India as well as in South Asia. For more than several centuries, it is being widely used for its medicinal properties. Objective: The objective of this study was to evaluate the biochemical changes in alloxan-induced diabetic rats treated with methanolic leaf extracts of $A$. marmelos. Materials and Methods: Six treatment groups, namely control, diseased, standard (glimepiride), low dose (100 mg/ $/ \mathrm{kg})$, medium dose $(250 \mathrm{mg} / \mathrm{kg})$, and high dose $(500 \mathrm{mg} / \mathrm{kg})$ of methanolic leaf extracts, were used in the study. The biochemical effects were evaluated by the determination of bodyweight, blood glucose, serum glutamic oxaloacetic transaminase (SGOT), serum glutamic pyruvic transaminase (SGPT), total proteins, serum albumin, serum creatinine, and alkaline phosphatase. Results: A significant increase in the bodyweight of the animals was observed in the high-dose treated animals $(350.0 \pm 6.15)$ when compared to the diseased group animals $(241.0 \pm 7.23)$. A significant decrease in the blood glucose, SGOT, and SGPT levels was observed in the high-dose treated animals $(142.3 \pm 20.52,71.6 \pm 4.8$, and $24.5 \pm 2.42)$ when compared to the diseased group animals $(292.8 \pm 29.34,146.3 \pm 11.12$, and $74.5 \pm 2.88$ ), respectively. Similarly, total proteins, serum albumin, serum creatinine, and alkaline phosphatase levels of the high-dose treated animals were also significantly decreased $(6.1 \pm 0.26,4.2 \pm 0.22$, $0.4 \pm 0.18$, and $109.2 \pm 14.58$ ) when compared to the diseased group animals $(9.7 \pm 0.27,5.4 \pm 0.26,1.0 \pm 0.22$, and $257.2 \pm 8.22)$, respectively. Conclusion: Through the biochemical changes, it is evident that the high dose of methanolic leaf extract of $A$. marmelos can be used in the treatment of diabetes and its complications.
\end{abstract}

Key words: Aegle marmelos, alloxan, bael, diabetes, rutaceae

\section{SUMMARY}

- The presence of flavonoids in the methanolic leaf extracts of Aegle marmelos has yielded the antidiabetic activity and therefore can be used in the treatment of diabetes and its complications.

\section{Antidiabetic activity of Aegle marmelos leaf extracts}

Preparation of Extracts and Phytochemical Evaluation

\section{1}

Acute toxicity study and evaluation of antidiabetic activity in rats

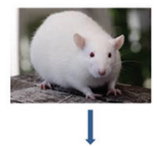

Evaluation of biochemical changes including blood glucose

1

Methanol leaf extract showed significant antidiabetic activity due to the presence of flavonoids

Abbreviations Used: SGPT: Serum glutamic pyruvic transaminase; SGOT: Serum glutamic oxaloacetic transaminase.

Correspondence:

Dr. Padmavathi Pamulapati, Department of Zoology and Aquaculture Acharya Nagarjuna University, Guntur, Andhra Pradesh, India. E-mail: padmapin@yahoo.com DOI: 10.4103/pr.pr_53_19

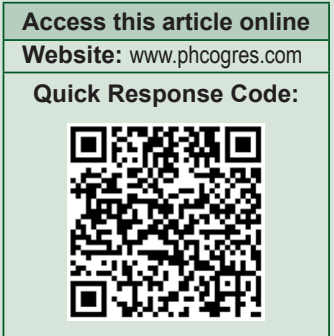

\section{INTRODUCTION}

Natural products have a special place in pharmaceutical research. During their long evolution and selection, they have acquired qualities mostly in connection with biological functions of animal or plant organisms. In addition, natural products are noted for their highly complex molecular architectures, and they show amazing arrangements of functional groups, strained ring systems, and other attractive structural attributes. Traditional knowledge of medicinal plants has always guided the search for new cures. In spite of the advent of modern high-throughput drug discovery of valuable drugs, traditional plants are often economical, locally available, and consumable raw or as simple medicinal preparation. Many vegetable drugs are used in preparations prescribed by practitioners of indigenous medicine in different regions; the common people use others as household remedies. ${ }^{[1]}$

Aegle marmelos (L.) Correa is a widely found plant in India as well as in South Asia. For more than several centuries, it is being widely used for its medicinal properties. Several phytocompounds have been isolated and characterized by various plant parts, namely alkaloids, terpenoids, tannins, phenols, cardiac glycosides, steroids, flavonoids, and saponins. These phytocompounds are reported to possess therapeutic potential for various diseases and disorders. ${ }^{[2]}$ Analgesic, antioxidant, anti-bacterial, antifungal, anticancer, antidiarrheal, immunomodulant, antihyperlipidemic, antiulcer, diuretic, antifilarial, and hepatoprotective activities have been reported in various plant extracts of the plants. ${ }^{[3-28]}$ Leaves are considered to be the most common sites of accumulation of phytocompounds in plants. Therefore, the present research work was aimed at the evaluation of biochemical changes in diabetic rats treated with methanolic leaf extracts from A. marmelos.

This is an open access journal, and articles are distributed under the terms of the Creative Commons Attribution-NonCommercial-ShareAlike 4.0 License, which allows others to remix, tweak, and build upon the work non-commercially, as long as appropriate credit is given and the new creations are licensed under the identical terms.

For reprints contact: reprints@medknow.com

Cite this article as: Birudu RB, Pamulapati P, Manoharan SK. Evaluation of biochemical changes in diabetic rats treated with Aegle marmelos (L.) methanolic leaf extract. Phcog Res 2020;12:127-30. 


\section{MATERIALS AND METHODS}

\section{Collection of plant material}

The leaves of A. marmelos (L.) were collected from Dolas Nagar, Tadepalle Mandal, Guntur District, Andhra Pradesh, India. Authentication was performed by Dr. P. Satya Narayana Raju, Plant Taxonomist, Department of Botany and Microbiology, Acharya Nagarjuna University, Guntur, Andhra Pradesh, India. The reference specimen is preserved in the Department of Botany, Acharya Nagarjuna University, Nagarjuna Nagar, Guntur.

\section{Preparation of plant extracts}

The collected leaves were washed thoroughly with water and shade dried. Methanolic leaf extracts were obtained by extracting powder with $85 \%$ ethanol by the Soxhlet extraction method for $72 \mathrm{~h}$. After completion of the extraction, the excess solvent was removed by rotary evaporation. The methanolic leaf extract was used for further evaluation of biochemical changes in alloxan-induced diabetes.

\section{Preliminary phytochemical analysis}

The methanolic leaf extract from A. marmelos (L.) was subjected to preliminary phytochemical analysis to assess the presence of various phytoconstituents; it revealed the presence of glycosides, saponins, tannins, and flavonoids.

\section{Animals}

Normal healthy male Wistar albino rats, 9-12 weeks old with an average weight of 200-250 g were procured from the Mahaveer Enterprises (CPCSEA Regd No: 146/99/CPCSEA), Bagh Amberpet, Hyderabad, India. They were housed in polypropylene cages and fed with a standard chow diet and water ad libitum.

The animals were acclimatized to the conditions by maintaining them at a temperature $25^{\circ} \mathrm{C} \pm 2^{\circ} \mathrm{C}$ and relative humidity $55 \pm 10$ at $12 \mathrm{~h}$ and each at dark and light cycle for about 7 days before dosing and during the commencement of the experiment.

All experimental procedures involving animals were conducted in accordance with the guidelines of Committee for the Purpose of Control and Supervision on Experiments on Animals (CPCSEA) with prior approval from the Institutional Animal Ethics Committee (IAEC Approval No. ANUCPS/IAEC/AM/P/26/2019) of College of Pharmaceutical Sciences, Acharya Nagarjuna University, Nagarjuna Nagar, Guntur, Andhra Pradesh, India.

\section{Treatment groups}

The biochemical changes were evaluated using the alloxan-induced diabetes model. ${ }^{[29]}$ A total of 36 rats were used. The rats were divided into six groups of six rats each: Group 1: vehicle treatment group, Group 2: disease control, Group 3: standard treatment (glimepiride $40 \mathrm{mg} / \mathrm{kg}$ ), Group 4: low dose of methanolic leaf extract (100 mg/kg), Group 5: medium dose of methanolic leaf extract $(250 \mathrm{mg} / \mathrm{kg})$, and Group 6: high dose $(500 \mathrm{mg} / \mathrm{kg})$. Plant leaf extracts were suspended in vehicle solution of $0.5 \%$ dimethyl sulfoxide and a dose of $1 \mathrm{ml} / \mathrm{kg}$, bodyweight was administered orally using an intragastric tube for 15-45 days to the respective groups.

\section{Chemicals}

Alloxan monohydrate was procured from Sigma Aldrich, Bangalore, India. All the other chemicals and solvents used in the study were of analytical grade and obtained from local suppliers.

\section{Acute toxicity studies}

The acute toxicity studies were carried out in accordance with OECD Test Guideline 423: Acute oral toxicity-acute toxic class method. The methanolic leaf extract of A. marmelos (L.) was found to be safe up to $2000 \mathrm{mg} / \mathrm{kg}$ bodyweight after oral administration of the test compound. $100 \mathrm{mg} / \mathrm{kg}, 250 \mathrm{mg} / \mathrm{kg}$, and $500 \mathrm{mg} / \mathrm{kg}$ were used for further animal pharmacological study.

Parameters evaluated: diabetes was induced by the administration of alloxan monohydrate (150 mg/kg bodyweight) with normal saline as a vehicle. After $72 \mathrm{~h}$, rats with blood glucose levels more than $150 \mathrm{mg} / \mathrm{dl}$ were selected for further biochemical evaluation. The blood glucose levels were estimated using the one-touch glucometer. The biochemical effects were evaluated by the determination of bodyweight, blood glucose, serum glutamic oxaloacetic transaminase (SGOT), serum glutamic pyruvic transaminase (SGPT), total proteins, serum albumin, serum creatinine, and alkaline phosphatase.

\section{Statistical analysis}

The results of the study were presented as mean \pm standard error of the mean. The statistical significance of the groups was determined using the one-way analysis of variance followed by Dunnett's test using GraphPad PRISM software. $P<0.05$ was considered as statistically significant.

\section{RESULTS AND DISCUSSION}

\section{Effects of methanolic leaf extracts on bodyweight of the treated animals}

A significant increase in the bodyweight of the animals was observed in the high-dose treated animals $(350.0 \pm 6.15)$ when compared to the diseased group animals $(241.0 \pm 7.23)$. The statistical significance between the groups was found to be $P<0.05$. The effects of methanolic leaf extracts on bodyweight of the treated rats are shown in Figure 1.

\section{Effects of methanolic leaf extracts on blood glucose of the animals}

A significant decrease in the blood glucose levels was observed in the high-dose treated animals $(142.3 \pm 20.52)$ when compared to the diseased group animals $(292.8 \pm 29.34)$. The statistical significance between the groups was found to be $P<0.05$. The effects of methanolic leaf extracts on blood glucose levels of the treated rats are shown in Figure 2.

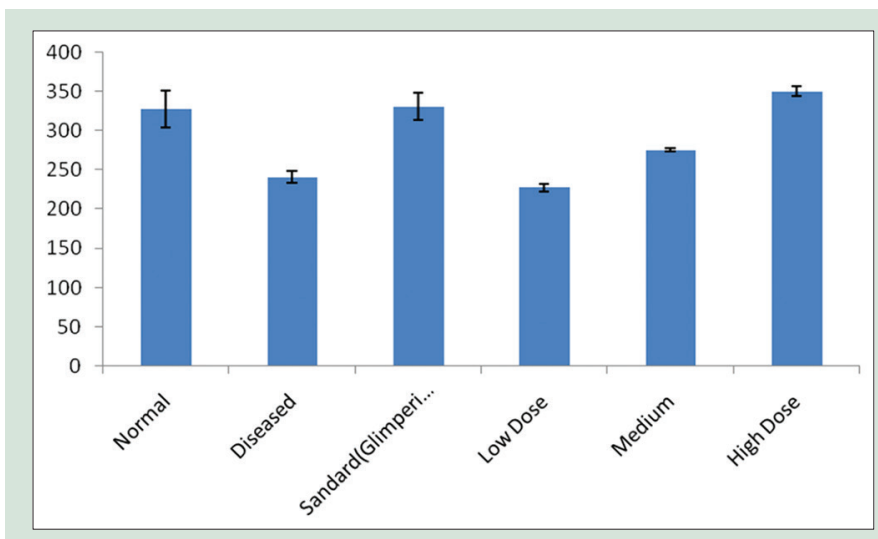

Figure 1: Effects of methanolic leaf extracts on bodyweight of the treated animals 


\section{Effects of methanolic leaf extracts on serum glutamic oxaloacetic transaminase of the animals}

A significant decrease in the SGOT levels was observed in the high-dose treated animals $(71.6 \pm 4.8)$ when compared to the diseased group animals $(146.3 \pm 11.12)$. The statistical significance between the groups was found to be $P<0.05$. The effects of methanolic leaf extracts on SGOT levels of the treated rats are shown in Figure 3.

\section{Effects of methanolic leaf extracts on serum glutamic pyruvic transaminase of the animals}

A significant decrease in the SGPT levels was observed in the high-dose treated animals $(24.5 \pm 2.42)$ when compared to the diseased group animals $(74.5 \pm 2.88)$. The statistical significance between the groups was

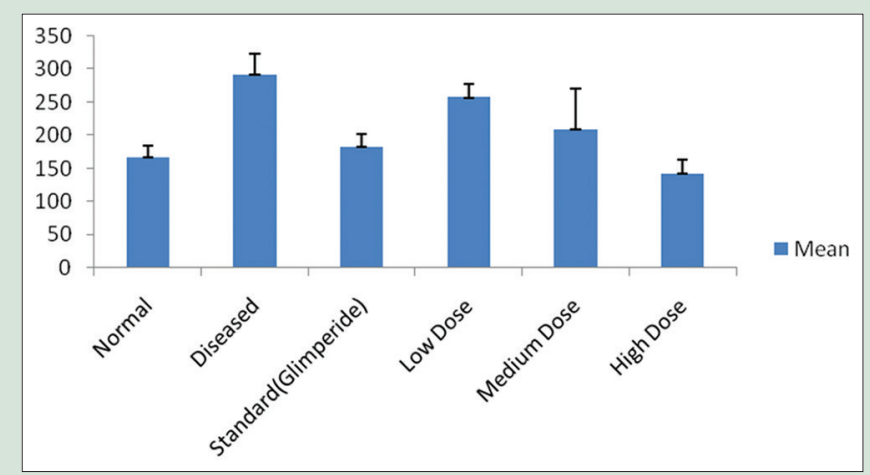

Figure 2: The effects of methanolic leaf extracts on blood glucose levels of the treated rats

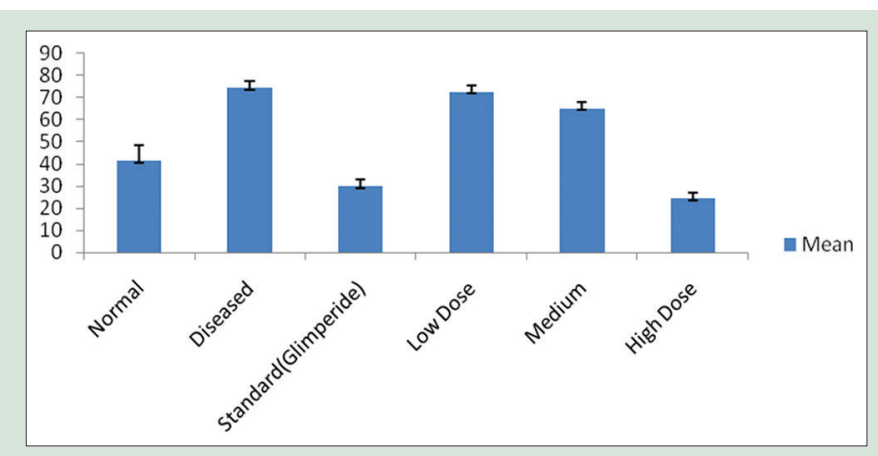

Figure 4: The effects of methanolic leaf extracts on serum glutamic pyruvic transaminase levels of the treated rats

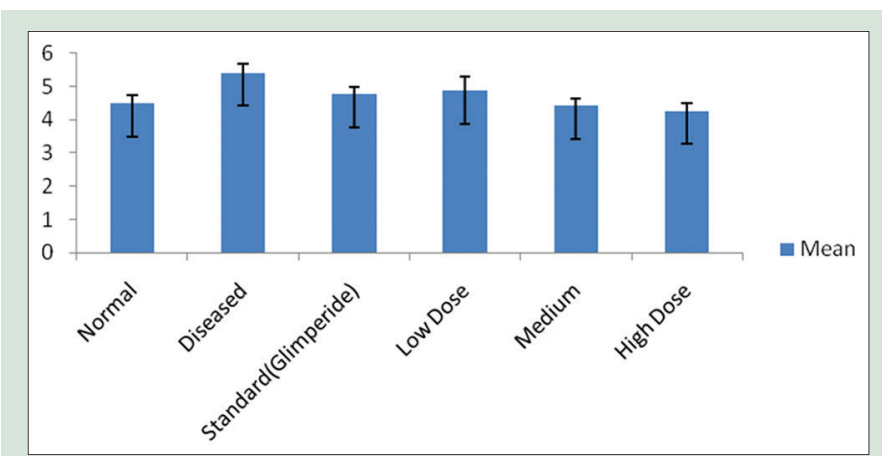

Figure 6: The effects of methanolic leaf extract on total proteins levels of the treated rats found to be $P<0.05$. The effects of methanolic leaf extract on SGPT levels of the treated rats are shown in Figure 4.

\section{Effects of methanolic leaf extracts on total proteins,} serum albumin, and serum creatinine levels of the animals

Similarly, total proteins, serum albumin, and serum creatinine levels of the high-dose treated animals were also significantly decreased $(6.1 \pm 0.26,4.2 \pm 0.22$, and $0.4 \pm 0.18)$ when compared to the diseased group animals $(9.7 \pm 0.27,5.4 \pm 0.26$, and $1.0 \pm 0.22)$, respectively. The statistical significance between the groups was found to be $P<0.05$. The effects of methanolic leaf extracts on total proteins, serum albumin, and serum creatinine levels of the treated rats are shown in Figures 5-7.

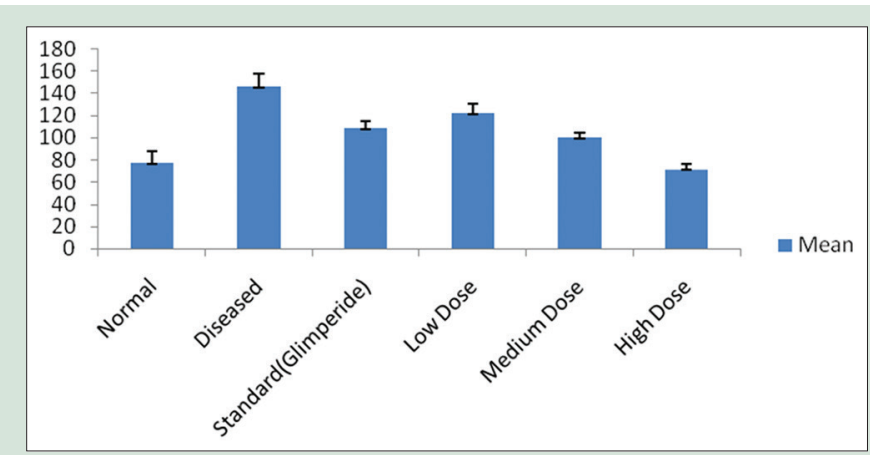

Figure 3: The effects of methanolic leaf extracts on serum glutamic oxaloacetic transaminase levels of the treated rats

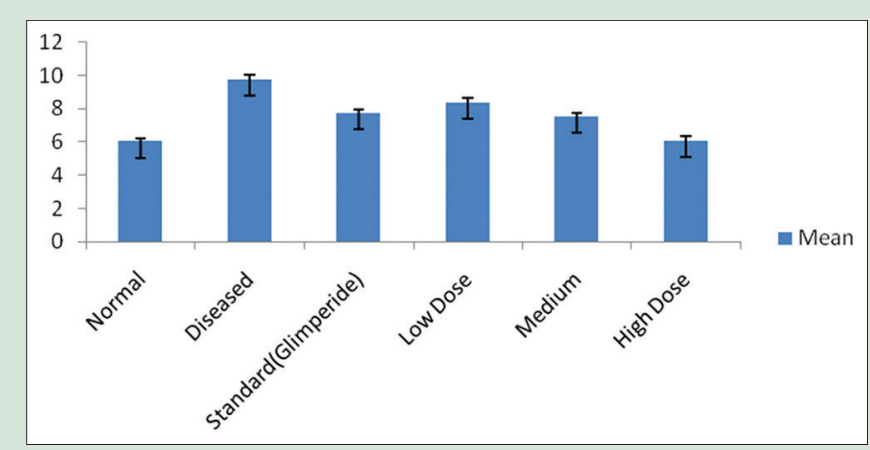

Figure 5: The effects of methanolic leaf extracts on total proteins of the treated rats

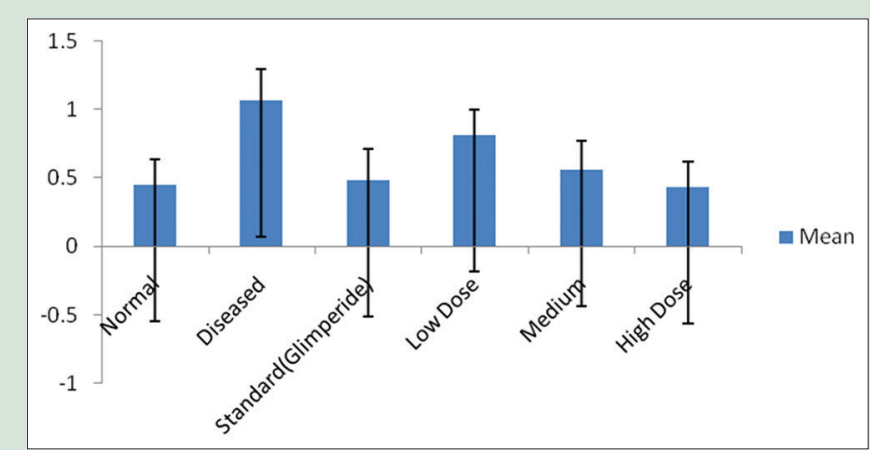

Figure 7: The effects of methanolic leaf extract on serum creatinine levels of the treated rats 


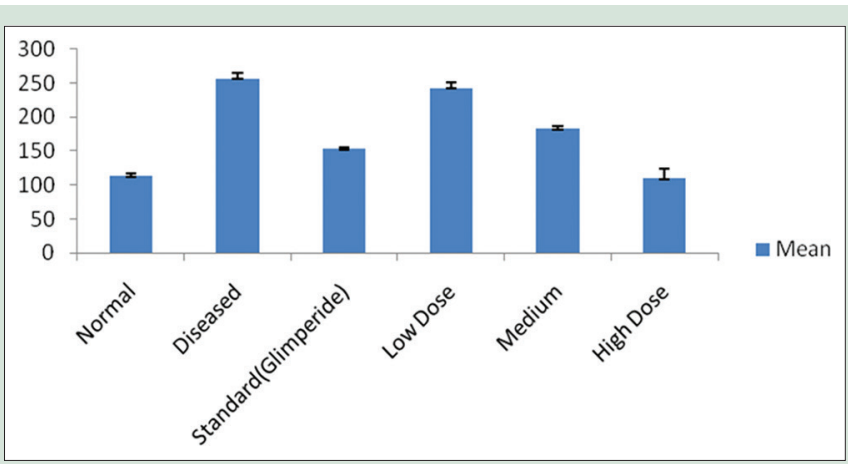

Figure 8: The effect of methanolic leaf extracts on serum creatinine levels of the treated rats

\section{Effects of methanolic leaf extracts on total proteins, serum albumin, and serum creatinine levels of the animals}

Alkaline phosphatase levels of the high-dose treated animals were also decreased $(109.2 \pm 14.58)$ when compared to the diseased group animals $(257.2 \pm 8.22)$. The statistical significance between the groups was found to be $P<1.0000$. The effects of methanolic leaf extracts on alkaline phosphatase levels of the treated rats are shown in Figure 8.

Earlier studies carried out on various fruit and bark extracts from the A. marmelos (L.) also showed significant pharmacological evidence for its therapeutic benefits in various animal models for diabetes and its related complications such as diabetic cataract and diabetic retinopathy. ${ }^{[30-32]}$

\section{CONCLUSION}

Through the biochemical changes, it is evident that the high dose of methanolic leaf extracts from $A$. marmelos can be used in the treatment of diabetes and its complications. The antidiabetic activity could be attributed to the presence of flavonoids in the extracts. However, there is a need for further cellular and molecular pharmacological studies to elucidate the exact mechanisms for its antidiabetic potential.

\section{Financial support and sponsorship}

Nil.

\section{Conflicts of interest}

There are no conflicts of interest.

\section{REFERENCES}

1. Buenz EJ, Schnepple DJ, Bauer BA, Elkin PL, Riddle JM, MotleyTJ. Techniques: Bioprospecting historical herbal texts by hunting for new leads in old tomes. Trends Pharmacol Sci 2004;25:494-8.

2. Mujeeb F, Bajpai P, Pathak N. Phytochemical evaluation, antimicrobial activity, and determination of bioactive components from leaves of Aegle marmelos. Biomed Res Int 2014;2014:1-11.

3. Kothari S, Kushwah A, Kothari D. Involvement of opioid and monoaminergic pain pathways in Aegle marmelos induced analgesia in mice. Indian J Pharmacol 2013;45:371-5

4. Rathee D, Kamboj A, Sidhu S. Augmentation of hepatoprotective potential of Aegle marmelos in combination with piperine in carbon tetrachloride model in wistar rats. Chem Cent J 2018;12:94.

5. Ibrahim NA, Mohammed MM, Aly HF, Ali SA, Al-Hady DA. Efficiency of the leaves and fruits of Aegle marmelos methanol extract (L.) Correa and their relative hepatotoxicity induced by CCL4 and identification of their active constituents by using LC/MS/MS. Toxicol Rep 2018;5:1161-8.

6. Rejiniemon TS, Arasu MV, Duraipandiyan V, Ponmurugan K, Al-Dhabi NA, Arokiyaraj S, et al. In-vitro antimicrobial, antibiofilm, cytotoxic, antifeedant and larvicidal properties of novel quinone isolated from Aegle marmelos (Linn.) Correa. Ann Clin Microbiol Antimicrob 2014;13:48.
7. Bhatti R, Singh J, Saxena AK, Suri N, Ishar MP. Pharmacognostic standardisation and antiproliferative activity of Aegle marmelos (L.) Correa leaves in various human cancer cell lines. Indian J Pharm Sci 2013;75:628-34.

8. Kumar S, Mahaseth RK, Tiwari M, Sehgal R, Rajora P, Mathur R. Interaction of aqueous leaf extract of Aegle marmelos (L.) Corr. with cholinergic, serotonergic and adrenergic receptors: An ex vivo study. Indian J Pharmacol 2015;47:109-13.

9. Balakumar S, Rajan S, Thirunalasundari T, Jeeva S. Antifungal activity of Aegle marmelos (L.) Correa (Rutaceae) leaf extract on dermatophytes. Asian Pac J Trop Biomed 2011;1:309-12.

10. Mujeeb F, Khan AF, Bajpai P, Pathak N. Phytochemical Study of Aegle marmelos chromatographic elucidation of polyphenolics and assessment of antioxidant and cytotoxic potential. Pharmacogn Mag 2018;13:S791-800.

11. Rana BK, Singh UP, Taneja V. Antifungal activity and kinetics of inhibition by essential oil isolated from leaves of Aegle marmelos. J Ethnopharmacol 1997; 57:29-34.

12. Kaushik P, Kumar S. Data of de novo assembly of the leaf transcriptome in Aegle marmelos. Data Brief 2018;19:700-3.

13. Subramaniam D, Giridharan $P_{1}$ Murmu N Shankaranarayanan NP, May R, Houchen CW, et al. Activation of apoptosis by 1-hydroxy-5,7-dimethoxy-2-naphthalene-carboxaldehyde, a novel compound from Aegle marmelos. Cancer Res 2008;68:8573-81.

14. Brijesh S, Daswani P, Tetali P, Antia N, Birdi T. Studies on the antidiarrhoeal activity of Aegle marmelos unripe fruit: Validating its traditional usage. BMC Complement Altern Med 2009;9:47.

15. Nair J, Velpandian T, Das US, Sharma P, Nag T, Mathur SR, et al. Molecular and metabolic markers of fructose induced hepatic insulin resistance in developing and adult rats are distinct and Aegle marmelos is an effective modulator. Sci Rep 2018;8:15950.

16. Govinda HV, Asdaq SM. Immunomodulatory potential of methanol extract of Aegle marmelos in animals. Indian J Pharm Sci 2011;73:235-40.

17. Reddy VP, Urooj A. Antioxidant properties and stability of Aegle marmelos leaves extracts. J Food Sci Technol 2013;50:135-40.

18. Jayachandran Nair CV, Ahamad S, Khan W, Anjum V, Mathur R. Development and validation of High-performance thin-layer chromatography method for simultaneous determination of polyphenolic compounds in medicinal plants. Pharmacognosy Res 2017;9:S67-73.

19. Chockalingam V, Kadali SS, Gnanasambantham P. Antiproliferative and antioxidant activity of Aegle marmelos (Linn.) leaves in Dalton's Lymphoma Ascites transplanted mice. Indian J Pharmacol 2012;44:225-34.

20. Lalremruta $V$, Prasanna GS. Evaluation of protective effect of Aegle marmelos Corr. in an animal model of chronic fatigue syndrome. Indian J Pharmacol 2012;44:351-9.

21. Asghar N, Mushtaq Z, Arshad MU, Imran M, Ahmad RS, Hussain SM. Phytochemical composition, antilipidemic and antihypercholestrolemic perspectives of Bael leaf extracts. Lipids Health Dis 2018;17:68.

22. Ilavarasan JR, Monideen S, Vijayalakshmi M. Antiulcer activity of Aegle marmelos Linn. Anc Sci Life 2002:21:256-9.

23. Vinodhini R. Detoxifying effect of Nelumbo nucifera and Aegle marmelos on hematological parameters of common Carp (Cyprinus carpio L.). Interdiscip Toxicol 2010;3:127-31.

24. Parmar NA, Patel BR, Nariya MB. A comparative experimental study to evaluate Mutrala (diuretic) activity of Bilva Moola and Patra (Aegle marmelos Corr.). Ayu 2014;35:344-7.

25. Perumal Samy R, Manikandan J, Al Qahtani M. Evaluation of aromatic plants and compounds used to fight multidrug resistant infections. Evid Based Complement Alternat Med 2013;201:1-17.

26. Sharma RD, Veerpathran AR, Dakshinamoorthy G, Sahare KN, Goswami K, Reddy MV. Possible implication of oxidative stress in anti filarial effect of certain traditionally used medicinal plants in vitro against Brugia malayi microfilariae. Pharmacognosy Res 2010;2:350-4.

27. Tarak D, Namsa ND, Tangjang S, Arya SC, Rajbonshi B, Samal PK, et al. An inventory of the ethnobotanicals used as anti-diabetic by a rural community of Dhemaji district of Assam, Northeast India. J Ethnopharmacol 2011;138:345-50.

28. Liagat I, Riaz N, Saleem QU, Tahir HM, Arshad M, Arshad N. Toxicological evaluation of essential oils from some plants of rutaceae family. Evid Based Complement Alternat Med 2018;2018:1-7.

29. Yadav JP, Saini S, Kalia AN, Dangi AS. Hypoglycemic and hypolipidemic activity of ethanolic extract of Salvadora oleoides in normal and alloxan-induced diabetic rats. Indian J Pharmacol 2008;40:23-7.

30. Ponnachan PT, Paulose CS, Panikkar KR. Effect of leaf extract of Aegle marmelose in diabetic rats. Indian J Exp Biol 1993;31:345-7.

31. Parveen A, Kim JH, Oh BG, Subedi L, Khan Z, Kim SY. Phytochemicals: Target-based therapeutic strategies for diabetic retinopathy. Molecules 2018;23. pii: E1519.

32. Santoshkumari KS, Devi KS. Hypoglycemic effect of a few medicinal plants. Anc Sci Life 1990;9:221-3. 